\title{
Behavioral alterations and Fos protein immunoreactivity in brain regions of bile duct-ligated cirrhotic rats
}

\author{
LUCIANA LE SUEUR-MALUF ${ }^{1}$, MILENA B. VIANA ${ }^{1}$, MÁRCIA R. NAGAOKA ${ }^{1}$, \\ ANA LAURA B. AMORIM ${ }^{1}$, AMANDA N. CARDOSO ${ }^{1}$, BRUNA C. RODRIGUES ${ }^{1}$, \\ NATÁLIA F. MENDES ${ }^{1}$, JACKSON C. BITTENCOURT ${ }^{2}$ and ISABEL C. CÉSPEDES ${ }^{1}$ \\ ${ }^{1}$ Departamento de Biociências, Universidade Federal de São Paulo/UNIFESP, \\ Rua Silva Jardim, 136, 11015-020 Santos, SP, Brasil \\ ${ }^{2}$ Laboratório de Neuroanatomia Química, Departamento de Anatomia, Instituto de Ciências Biomédicas, \\ Universidade de São Paulo/USP, Av. Prof Lineu Prestes, 2415, 05508-900 São Paulo, SP, Brasil \\ Manuscript received on July 25, 2013; accepted for publication on August 24, 2014
}

\begin{abstract}
Hepatic encephalopathy (HE) encompasses a variety of neuropsychiatric symptoms, including anxiety and psychomotor dysfunction. Although HE is a frequent complication of liver cirrhosis, the neurobiological substrates responsible for its clinical manifestations are largely unclear. In the present study, male Wistar rats were bile duct-ligated (BDL), a procedure which induces liver cirrhosis, and on the $21^{\text {st }}$ day after surgery tested in the elevated plus-maze (EPM) and in an open field for anxiety and locomotor activity measurements. Analysis of Fos protein immunoreactivity ( $F o s$-ir) was used to better understand the neurobiological alterations present in BDL animals. Plasma levels of ammonia were quantified and histopathological analysis of the livers was performed. BDL rats showed a significant decrease in the percentage of entries and time spent in the open arms of the EPM, an anxiogenic effect. These animals also presented significant decreases in Fos-ir in the lateral septal nucleus and medial amygdalar nucleus. Their ammonia plasma levels were significantly higher when compared to the sham group and the diagnosis of cirrhosis was confirmed by histopathological analysis. These results indicate that the BDL model induces anxiogenic results, possibly related to changes in the activation of anxiety-mediating circuitries and to increases in ammonia plasma levels.
\end{abstract}

Key words: anxiety, bile-duct ligation, Fos-immunoreactivity, hepatic encephalopathy, locomotor activity.

\section{INTRODUCTION}

Liver cirrhosis is a chronic disease, commonly caused by alcohol abuse or hepatitis $\mathrm{C}$, which may be defined as the histological development of regenerative nodules encircled by fibrous bands as a reaction to liver injury (Schuppan and Afdhal 2008). Some of the clinical outcomes of cirrhosis: decreased liver function, increased portal hypertension and

Correspondence to: Isabel Cristina Céspedes

E-mail: isabel.cespedes@unifesp.br hepatocellular carcinoma. Circulatory abnormalities, i.e. splanchnic vasodilation, vasoconstriction and kidney hypoperfusion, retention of salt/water and augmented cardiac output, which also accompany cirrhosis, are closely related to the vascular hepatic alterations and portal hypertension (Schuppan and Afdhal 2008). Liver cirrhosis is one of the major health problems in the Western world. The disease demands expensive treatments and presents high mortality rates (Schuppan and Afdhal 
2008, Weissenborn et al. 1997). The prevalence of liver cirrhosis is approximately 35 per 100,000 of the population overall, with an incidence of approximately 5 per 100,000 per year. It is the $12^{\text {th }}$ leading cause of hospitalizations and death in the US (Kim et al. 2000).

One of the main complications of liver cirrhosis is hepatic encephalopathy (HE) (Butterworth 2003, Garcia-Tsao 2001). This term has been used to identify a broad variety of neuropsychiatric abnormalities (i.e., anxiety and depression symptoms, altered sleep patterns and cognitive and psychomotor impairments), which can occur in cirrhotic patients, after exclusion of other neurological and/or metabolic causes (Butterworth 2003, Sunmonu et al. 2012). HE occurs in nearly $30-45 \%$ of patients with liver cirrhosis (Khungar and Poordad 2012). When HE is severe, patients may develop variable degrees of confusion and even coma (Ferenci et al. 1998).

The pathogenesis of HE is largely unknown (Gerber and Schomerus 2000), although some theories have been proposed. It is known that inadequate hepatic detoxification causes accumulation of circulating gut-derived toxins of nitrogenous compounds, in particular ammonia (Phongsamran et al. 2010). Peripheral glutamine synthetase may function as a substitute ammonia detoxification pathway in patients with reduced ability for detoxification of ammonia into urea. Glutamine synthesis also occurs in astrocytes (Butterworth 2003, Vaquero et al. 2003). It has been proposed that this could cause astrocyte swelling and possibly be responsible for some of the neurological abnormalities present in HE (Phongsamran et al. 2010). It is also suggested that inflammatory cytokines play a fundamental role in the pathogenesis of HE (Phongsamran et al. 2010). Additionally, alterations of some neurotransmitter systems, such as glutamate, GABA, serotonin, catecholamines and endogenous opioids, have been implicated in the ethiopathogeny of HE (Albrecht and Jones 1999, Butterworth 2003). Apart from these few "working hypotheses", however, the neurobiological substrates that may be responsible for the clinical manifestations of HE are largely unclear.

The purpose of the present study was to investigate anxiety and motor behavior in bile duct-ligated (BDL) rats, an experimental model of cirrhosis. The validity of the BDL model for studying behavioral and biochemical alterations of liver cirrhosis has been well documented (Assimakopoulos and Vagianos 2009, Blei and Córdoba 2001). The model causes jaundice and impairment of liver function, and also induces fibrosis, portal hypertension, portalsystemic shunting, and inflammatory activation (Assimakopoulos and Vagianos 2009, Blei and Córdoba 2001).

For the evaluation of anxious behavior, BDL and sham animals were tested in the elevated plus-maze (EPM) (Cruz et al. 1994, Pellow et al. 1985). Although increases in anxiety are frequently described for HE patients, in animal models, anxiety-related effects are difficult to interpret due to confounding psychomotor impairments. Thus, to separate anxiety from locomotor activity assessment, three different indices of motor activity (Cruz et al. 1994, Royce 1977) were also obtained from the same animals: the number of entries into the closed arms of the EPM, the number of lines crossed and the frequency of rearings in an open field.

After the behavioral tests, analysis of Fos protein immunoreactivity (Fos-ir) was used to better understand the neurobiological alterations induced in BDL animals. For both experimental groups, plasma levels of ammonia were quantified and histopathological analysis of the liver was performed at the end of the experiments.

\section{MATERIALS AND METHODS}

\section{SUBJECTS}

Male Wistar rats (Federal University of São Paulo, CEDEME, Brazil), weighing approximately 280 g, were housed in groups of 5-6 per cage. After surgery, 
animals were housed in pairs in Plexiglas-walled cages until testing on the 21st day after surgery. Room temperature was controlled $\left(22 \pm 1^{\circ} \mathrm{C}\right)$ and a light-dark cycle was maintained on a 12-h onoff cycle (lights on at $7 \mathrm{am}$ ). Food and water were available ad libitum throughout the experiments. The present study was approved by the Ethical Committee for Animal Research of the Federal University of São Paulo (UNIFESP) under the number 1800/09 and was performed in compliance with the recommendations of the SBNeC (Brazilian Society of Neuroscience and Behavior), which are based on the US National Institutes of Health Guide for Care and Use of Laboratory Animals.

\section{SURGERY - BILE DUCT-LigATION}

One day after their arrival, rats were anaesthetized with an IP injection of ketamine hydrochloride (80 mg/kg; Agribrands, Brazil) and xylazine (10 $\mathrm{mg} / \mathrm{kg}$; Agribrands, Brazil) and laparotomy was performed. The common bile duct was isolated and tied in two locations: in the proximal portion and in the distal part of the duct. The ligatures were then tightened and the incision sutured. Sham-animals were subjected to the same surgical procedure, except the bile duct was not ligated.

After surgery, all animals were submitted to anti-inflammatory and analgesic care. They were treated orally with two drops of dipyrone (500 $\mathrm{mg} / \mathrm{mL}$, Novalgina, Safoni Aventis, Brazil), and received a solution of water and sucrose $(10 \%)$ plus acetylsalicylic acid $(0.2 \mathrm{mg} / \mathrm{ml}$, Aspirin, Bayer, Brazil), which they were allowed to drink ad libitum for a period of 24 hours.

APPARATUS

\section{Elevated plus-maze (EPM)}

The EPM was made of wood and had four arms of equal dimensions $(50 \times 10 \mathrm{~cm})$. Two arms, enclosed by $40 \mathrm{~cm}$ high walls, were perpendicular to two opposed open arms. To avoid falls, the open arms were surrounded by a $1 \mathrm{~cm}$ high Plexiglas rim. The four arms delimited a central area of $10 \mathrm{~cm}^{2}$. The whole apparatus was elevated $50 \mathrm{~cm}$ above the floor.

\section{Open field}

The open field test was performed in a round arena $(60 \times 60 \mathrm{~cm})$, with the floor divided into 12 parts, and walls $50 \mathrm{~cm}$ high.

Luminosity at the level of the maze arms and at the center of the open field was 60 lux. The experimental sessions were recorded on DVDs by a vertically mounted videocamera, linked to a monitor placed in an adjacent room. An observer blind to the treatment conditions, later analyzed the recorded experimental sessions.

\section{BEHAVIORAL ANALYSIS}

On the 21st day after surgery, sham and BDL ( $\mathrm{N}=$ 9 per treatment group) animals were submitted to the behavioral tests. Animals were tested on the $21^{\text {st }}$ day after surgery since previous studies showed that 3 to 4 weeks after bile-duct ligation the induction of a cirrhotic state is obtained (see Kontouras et al. 1984, Pereira et al. 2008).

For the behavioral tests, rats were taken in their home cages to the experimental room and individually placed in the center of the EPM. They were then allowed to freely explore the maze for $5 \mathrm{~min}$. The standard measures (number of entries into open and closed arms, and time spent in open and closed arms) (see references Cruz et al. 1994, Pellow et al. 1985) were recorded for posterior analysis. After quantification, measurements of number of entries and time spent in open arms were transformed into percentages (percentage of entries in open arms $=$ [number of entries in open arms/ total number of entries] $\mathrm{x} 100$; percentage of time in open arms $=$ [time in open arms/total time $] \times 100)$. It has been previously shown (Cruz et al. 1994) that the two critical measurements that represent the reverse of anxiety are: the percentage of open arm entries and the percentage of time spent in open arms. On the other hand, the critical measurement 
for locomotor activity seems to be the total number of closed arm entries (Cruz et al. 1994).

Immediately after the tests with the EPM, animals were placed in the center of the open field and also allowed to freely explore for $5 \mathrm{~min}$ for posterior measurements of the total number of lines crossed and frequency of rearings.

After each experimental session with the EPM or open field, each apparatus was cleaned with a solution of $20 \%$ ethanol and dried.

\section{Measurements of Ammonia Plasma LeVels}

On the morning of the $22^{\text {nd }}$ day, animals were anesthetized with ketamine/xylazine as described above and blood was collected from the left ventricle after thoracic aperture, before perfusion, placed in heparinized tubes and centrifuged for $15 \mathrm{~min}$ at $1500 \mathrm{rpm}$, at $4^{\circ} \mathrm{C}$. Plasma ammonia concentrations were analyzed via endpoint colorimetric assay (Vitros 750, Johnson \& Johnson Clinical Diagnostics, USA). Briefly, ammonium ions are converted to gaseous ammonia and pass through a semipermeable membrane layer before reacting with bromophenol blue.

\section{FOS PROTEIN IMMUNOREACTIVITY (FOS-IR)}

Immediately after blood collection, six animals from each group were perfused with $\approx 100 \mathrm{ml}$ of $0.9 \%$ saline for approximately $1 \mathrm{~min}$, followed by $500-700 \mathrm{ml}$ of $4 \%$ formaldehyde (from paraformaldehyde heated to $60-65^{\circ} \mathrm{C}$ ) and $\mathrm{H}_{2} \mathrm{O}$ at $4^{\circ} \mathrm{C}, \mathrm{pH} 9.5$, for approximately $25 \mathrm{~min}$. Their brains were post-fixed for $1 \mathrm{~h}$ in the same fixative and were kept in a buffer containing $20 \%$ sucrose overnight at $4^{\circ} \mathrm{C}$. Regularly spaced series $(5 \times 1$ in-5) of $30 \mu \mathrm{m}$-thick frozen sections were cut in the frontal plane, collected in ethylene glycolbased cryoprotectant solution and stored at $-20^{\circ}$ C for later determination of Fos-ir. Labeled neurons were identified using a polyclonal antiplasma raised in rabbits against synthetic human Fos (anti-Fos, 1:20,000; Oncogene, USA).
Immunohistochemistry was performed using a conventional avidin-biotin immunoperoxidase protocol (Hsu and Raine 1981) and Vectastain Elite reagents (Vector Laboratories, USA). Tissue was pretreated with hydrogen peroxide $(0.3 \%$; Sigma, USA) before addition of the primary antibody to squelch endogenous peroxidase activity in the tissue. The reaction with diaminobenzidine-DAB (0.05\%; Sigma, USA) was amplified using nickel ammonium sulfate and the sections were then mounted on gelatin-coated slides.

\section{DATA COLLECTION AND ANALYSIS}

We quantified Fos-ir neurons in sections, under bright-field illumination using the Image-Pro Plus software (Media Cybernetics, USA), having as reference the following AP coordinates (Paxinos and Watson 2008): amygdala = bregma -2.92; dorso and ventromedial hypothalamic nuclei = bregma -2.92 ; paraventricular nucleus of the hypothalamus and anterior hypothalamic area (central part) = bregma -1.80 ; pre-frontal cortex $=$ bregma +1.68 ; lateral septal nucleus $=$ bregma +1.68 ; bed nucleus of the stria terminalis (medial and lateral divisions) $=$ bregma -0.7 ; hippocampus $=$ bregma $-2,80$. Sections were analyzed by an observer blind to the treatment conditions. Cells were considered Fos-ir if their nuclei contained dark, punctate gray-black immunolabeling, and were counted using constant minimum and maximum OD and object size criteria, which were validated by means of visual counts.

\section{HistopatholOGICAL ANALYSIS}

To confirm the cirrhotic state, liver fragments from the two groups were collected for histopathological examinations. The samples were fixed in $10 \%$ buffered formalin, routinely processed and embedded in paraplast (Histosec, Merck, USA). Sections of 5-7 $\mu \mathrm{m}$ were stained with hematoxylin and eosin (H.E., Merck, USA) and observed and photographed using a light microscope (Axio Observer D1, Zeiss, USA). 


\section{STATISTICAL ANALYSIS}

Unpaired Student-T test was used to analyze behavioral data, ammonia plasma levels and Fos-ir. A value of $\mathrm{p}<0.05$ was considered significant.

\section{RESULTS}

\section{Elevated Plus-Maze (EPM) AND OPEN FieLd}

Figure 1 shows the percentage of entries (left panel) and time (right panel) spent in the open arms of the EPM. The unpaired Student T-test indicated that the BDL group showed a significant decrease in the percentage of entries $(\mathrm{T}(9.19)=11.76 ; \mathrm{P}<0.001)$ and time spent in the open arms of the EPM (T (16) $=2.99 ; \mathrm{P}=0.009$ ).

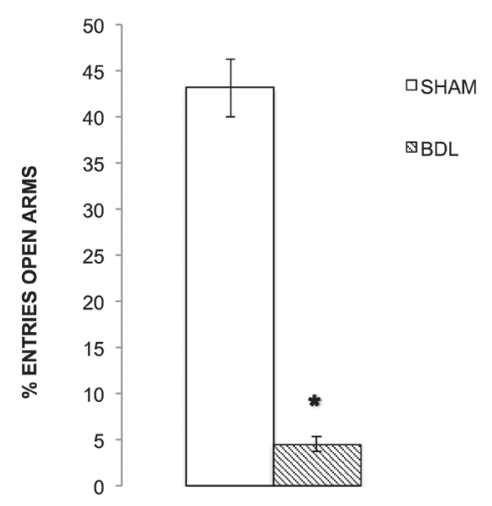

Table I shows the number of entries into the closed arms of the EPM, the total number of lines crossed and the frequency of rearings in the open field. No significant differences were observed between the two groups for any of the parameters. Nevertheless, regarding the number of lines crossed the statistical result obtained, was close to statistical significance $(\mathrm{T}(16)=1.89 ; \mathrm{P}=0.08)$.

\section{FOS IMMUNOREACTIVITY (FOS-IR)}

Table II shows Fos-ir for the different anxietyrelated regions analyzed. The unpaired Student-T test showed that for the intermediate lateral septal nucleus $(\mathrm{T}(5.26)=3.39 ; \mathrm{P}=0.018)($ Fig 2, upper

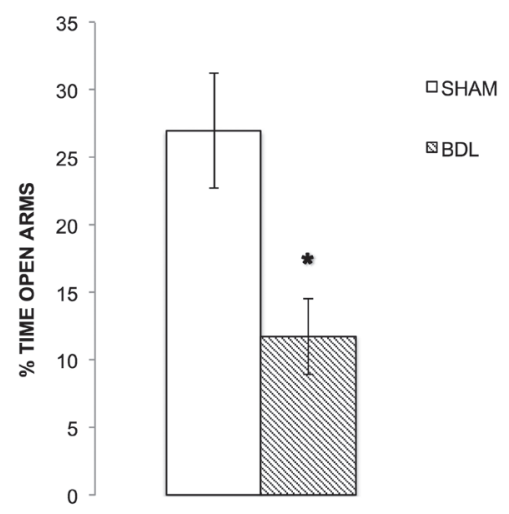

Figure 1 - Percentage (mean \pm SEM) of entries (left panel) and time spent (right panel) in the open arms of the elevated plus-maze by sham and bile duct-ligated (BDL) animals. $\mathrm{N}=9$ per treatment group. $* \mathrm{P}<0.05$ with respect to the sham group (unpaired Student T-test).

TABLE I

Number (mean \pm SEM) of closed arms entries in the elevated plus-maze and crossings and rearings in the open field by sham and bile duct-ligated (BDL) animals.

\begin{tabular}{cccc}
\hline Treatments & $\begin{array}{c}\text { Closed Arms } \\
\text { Entries }\end{array}$ & Crossings & Rearings \\
\hline Sham & $9.67 \pm 0.94$ & $35.44 \pm 5.62$ & $13.00 \pm 1.69$ \\
BDL & $6.78 \pm 1.46$ & $22.78 \pm 3.63$ & $10.67 \pm 1.89$ \\
\hline
\end{tabular}

panel) and medial amygdalar nucleus (T(5.44) $=3.29 ; \mathrm{P}=0.019)$ (Fig 2, lower panel) the BDL group showed significant decreases in Fos-ir when compared to the sham group $(\mathrm{P}<0.05)$. There were no significant differences between BDL and sham animals for the other analyzed areas $(\mathrm{P}>0.05)$.

\section{Ammonia Plasma LeVELS}

Figure 3 shows ammonia levels on the $22^{\text {nd }}$ day after surgery for the two experimental groups. The unpaired Student-T test indicated that the BDL group presented significant increases in ammonia plasma levels when compared to sham animals $(\mathrm{T}(9.35)=-6.25 ; \mathrm{P}<0.001)$.

\section{HistopathologicAL ANALYSIS}

Figure 4 shows liver photomicrographs from the two experimental groups. Histopathological analysis showed that the livers of BDL animals were marked by disorganization of the lobular cytoarchitecture, with proliferation of portal and 
TABLE II

Number (mean \pm SEM) of Fos immunoreactive cells in pre-determined areas of anxiety-related regions of sham and bile duct-ligated (BDL).

\begin{tabular}{ccc}
\hline Structures & Sham & BDL \\
\hline Pre-frontal Cortex & $59.67 \pm 13.08$ & $58.33 \pm 10.13$ \\
CA1 and CA2 (hippocampus) & $7.50 \pm 5.74$ & $0.80 \pm 0.49$ \\
CA3 (hippocampus) & $4.00 \pm 2.31$ & $1.20 \pm 0.58$ \\
Dentate Gyrus (hippocampus) & $17.83 \pm 7.96$ & $3.60 \pm 1.75$ \\
Dorsolateral Septum & $6.50 \pm 2.81$ & $3.60 \pm 1.91$ \\
Intermediate Lateral Septum & $48.33 \pm 12.19$ & $6.50 \pm 1.96^{*}$ \\
Ventrolateral Septum & $57.50 \pm 24.00$ & $25.33 \pm 5.74$ \\
Bed Nucleus Stria Terminalis & $3.17 \pm 1.22$ & $2.26 \pm 8.67$ \\
Basolateral Amygdala & $12.33 \pm 3.97$ & $4.33 \pm 1.65$ \\
Basomedial Amygdala & $13.67 \pm 8.13$ & $5.00 \pm 2.89$ \\
Lateral Amygdala & $9.50 \pm 4.32$ & $8.33 \pm 2.03$ \\
Medial Amygdala & $41.83 \pm 10.67$ & $6.00 \pm 2.25 *$ \\
Central Amygdala & $16.00 \pm 8.78$ & $16.67 \pm 6.81$ \\
Dorsomedial Hypothalamus & $87.20 \pm 37.23$ & $14.17 \pm 2.56$ \\
Ventromedial Hypothalamus & $31.33 \pm 11.79$ & $21.83 \pm 5.88$ \\
Anterior Hypothalamus & $70.83 \pm 15.82$ & $48.17 \pm 11.11$ \\
Paraventricular Hypothalamus & $44.33 \pm 11.59$ & $40.00 \pm 9.88$ \\
\hline
\end{tabular}

$* \mathrm{P}<0.05$ with respect to sham animals (Unpaired Student-T test).

\section{Sham}
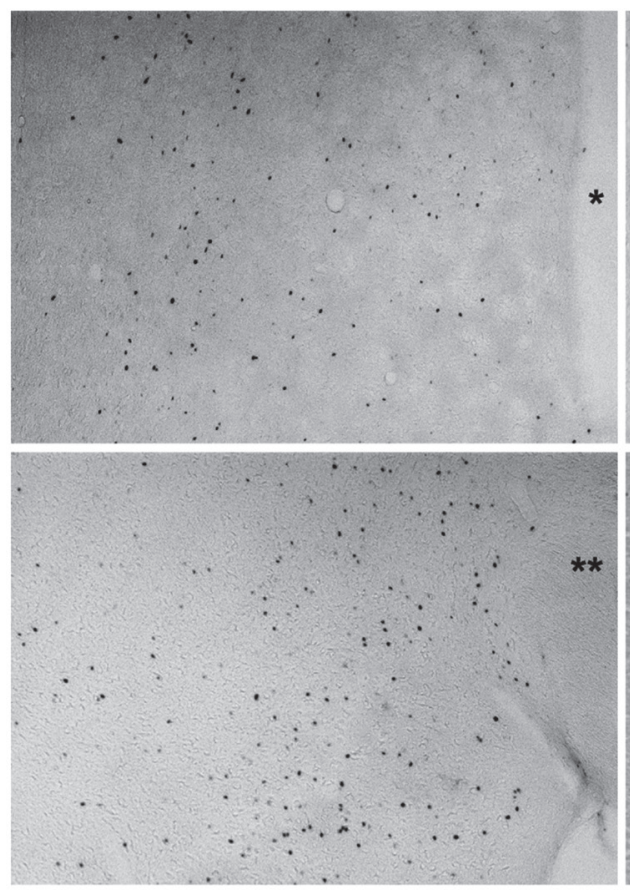

BDL
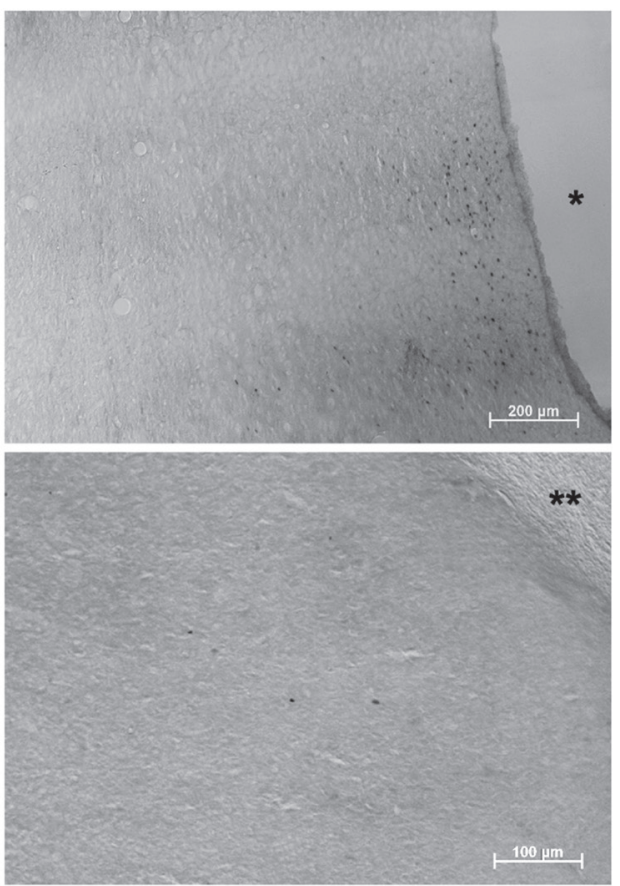

Figure 2 - Photomicrographs of FOS-immunoreactive cells (dark spots) in coronal sections through brain regions with significant decreases in Fos immunoreactivity after bile duct-ligation. Upper panel: Intermediate part of the lateral septal nucleus; Lower panel: Medial amygdalar nucleus. N=6 per treatment group. $\left(^{*}\right)$ lateral ventricle; $(* *)$ optic tract. Scale Bars: 100 and $200 \mu \mathrm{m}$. 


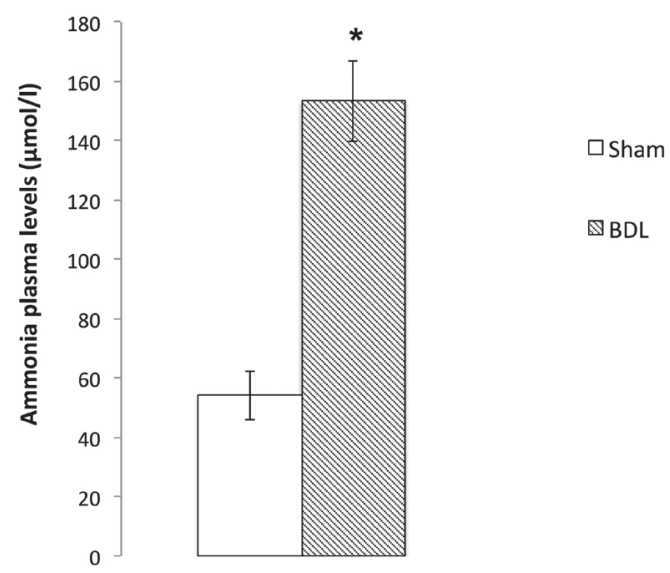

Figure 3 - Ammonia plasma levels $(\mu \mathrm{mol} / \mathrm{l})$ in sham and bile duct-ligated (BDL) animals. $\mathrm{N}=5$ (sham) and 7 (BDL). ${ }^{*} \mathrm{P}<0.05$ with respect to the sham group (unpaired Student T-test).

periportal biliary ductules, dilated portal spaces and areas of polymorphonuclear leukocyte infiltration. Fibrosis and hepatocytes in the process of cell death were also observed. None of these morphological alterations were observed in the sham group.

\section{DISCUSSION}

The results of the present study showed that BDL animals exhibited a significant decrease in the percentage of entries and time spent in the open arms of the EPM, without significant alterations in motor activity. These results are indicative of an increase in anxiety. BDL animals also showed a significant decrease in Fos-ir in the intermediate lateral septal nucleus and medial amygdalar nucleus. These neurobiological changes were accompanied by higher ammonia plasma levels and histopathological alterations of the liver tissue, thus confirming that the bile duct-ligation procedure was efficient in inducing liver cirrhosis.

The few studies that have verified anxietyrelated effects in BDL animals are contradictory, in part due to the interference of locomotor parameters. It has been shown, for instance, that the distance traveled in the center zone of an arena was
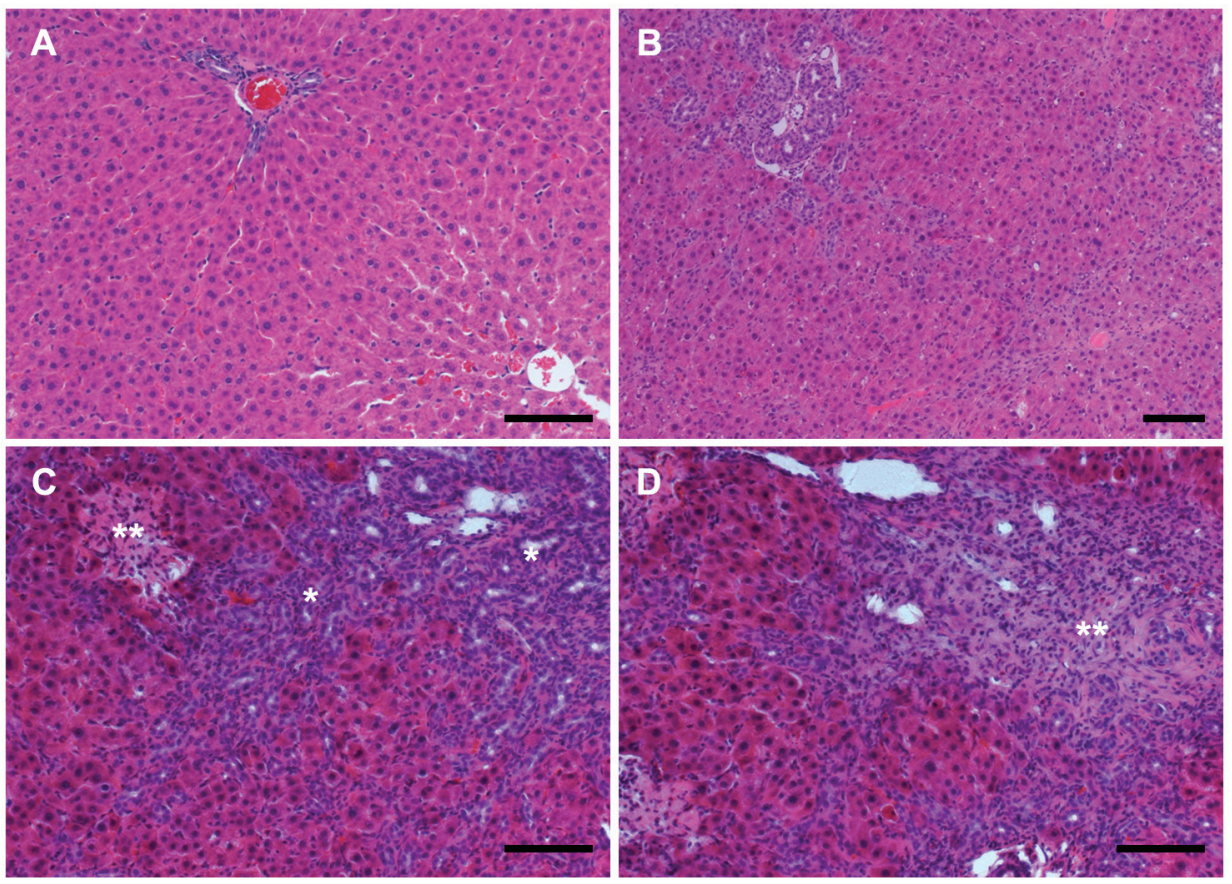

Figure 4 - Photomicrographs of liver sections of sham (A) and bile-duct ligated animals (BDL) (B-D). Livers of BDL animals presented disorganization of the lobular cytoarchitecture (B), with proliferation of portal and periportal biliary ductules $\left(\mathbf{C},,^{*}\right)$ and areas of fibrosis $(\mathbf{D}, * *)$, among strands of degenerating hepatocytes. None of these pathological alterations were observed in sham animals (A). Scale Bar: $100 \mu \mathrm{m}$. 
decreased in BDL rats (Leke et al. 2012). Usually, this pattern of behavior is interpreted as avoidance of the open area, and suggests anxiety behavior. Nevertheless, in the same study, measurements in the EPM did not show increases in anxiety. It is worth mentioning, however, that the indices that these authors used to evaluate anxiety in the EPM (percentage of entries and time spent in the closed arms) are not the ones traditionally used. Since the open space is the aversive stimulus in the EPM model, anxiety behavior is related to a decrease in the percentage of entries and time spent in the open arms (Cruz et al. 1994). In fact, closed arm entries correlate positively with locomotor activity and not with anxiety (Cruz et al. 1994). Thus, the results of this particular study do not allow the conclusion that no anxiety-related effects were found in BDL animals. Furthermore, in another study (Ahboucha et al. 2008) performed with rats with portacaval anastomosis tested in the EPM, no anxiety-related effects were found, but deficits in the animals' motor behavior were observed, thus compromising any conclusion regarding anxiety parameters.

On the other hand, the anxiogenic effects observed were consistent with clinical descriptions of HE patients (Butterworth 2003, Sakamoto et al. 2012). According to the West Haven scale (WHS) (for a review see Sakamoto et al. 2012), which measures stages of hepatic encephalopathy, anxiety symptoms are present in stage $2 \mathrm{HE}$ patients, indicating moderate impairment. In addition, another instrument largely used to diagnose HE, the Hepatic Encephalopathy Scoring Algorithm (HESA) - which combines clinical examination with neuropsychological tests when determining HE grades on a scale from 0-4 (absence-severe HE) - includes anxiety symptoms as clinical manifestations of stage 1. Thus, in our present study, the BDL model was effective in replicating this important symptom of HE.

It is noteworthy that both scales also include psychomotor impairment (slow responses, lethargy) as symptoms present in HE. According to the HESA, psychomotor impairment would describe a more severe grade of encephalopathy (stage 2 $\mathrm{HE})$. Although in some of the studies conducted with different animal models of HE, decreases in locomotor activity were observed (Ahboucha et al. 2008, Leke et al. 2012), in others, no motor alterations were found (Sergeeva et al. 2005). In fact, some studies have suggested that depending on the test used to measure motor activity, deficits may or may not be obtained. For instance, in a study also performed with the BDL model, Jover and coworkers (Jover et al. 2006) showed that although the rats presented a mild impairment of motor coordination in the rotarod, no significant differences were observed in the beam-walking test. If taken together, these clinical and experimental observations seem to suggest that depending on the degree of severity of the state of HE induced, and (possibly) on the test used to measure locomotion, motor deficits may or may not be detected.

Analysis of Fos-ir showed decreases in the pattern of activity of most brain regions analyzed, and in particular in the intermediate part of the lateral septal nucleus and in the medial amygdalar nucleus. It is important to emphasize, however, that the immunohistochemical analysis was performed $24 \mathrm{~h}$ after the behavioral tests. Therefore, these results are indicative of changes induced by the BDL model, and not by the anxiogenic stimulus itself.

Nevertheless, it is worth noting that both the lateral septum and the medial amygdala are regions that have traditionally been related to the modulation of anxiety. Several authors have emphasized the important role played by the lateral septum in the control of anxiety. Whether the nature of this control is inhibitory (Thomas 1988, Yadin et al. 1993) or facilitatory (Treit and Menard 2000) is still a matter of debate. As previously pointed out (de Andrade et al. 2012, Diniz et al. 2013) the septal region, together with the hippocampus, is one of the main structures of the so-called "Behavioral Inhibition System" (Gray 
and McNaughton 2001, Gray 1987, McNaughton and Corr 2004), activated when the animal is faced with a threat which involves approach-avoidance conflict. In this sense it is interesting to point out that increases in the anxious behavior in the EPM are accompanied by a decrease in risk-assessment (Cruz et al. 1994), which typically occurs in approach-avoidance conflict situations (Gray 1987, McNaughton and Corr 2004).

The medial amygdalar nucleus is functionally distinct from other amygdala nuclei (Canteras 2002, Maras and Petrulis 2010). It is known as the "vomeronasal amygdala" since it receives pheromone cues from the accessory olfactory bulb and olfatory inputs from the cortical amygdala (Kang et al. 2009, Kevetter and Winans 1981). These chemosignals bring information from opposite and same-sex individuals, thus providing the structure with critical information for the modulation of reproductive, social and defensive behaviors (Niimi et al. 2012). Indeed, a number of previous studies from our and other research groups have indicated the important role played by the medial amygdalar nucleus in the regulation of defense and anxiety-related responses (Diniz et al. 2013, Ferenci et al. 1998, Herdade et al. 2006, Ma and Morilak 2005). Although the majority of these studies measure increases in Fos-ir in response to anxiogenic stimuli (and in this sense measure state anxiety), studies directed towards the investigation of trait anxiety and thus performed with rat lines selectively bred for high anxiety-related behavior (see for instance Muigg et al. 2008) show an attenuated c-Fos response to repeated conditioned stimulus presentations in the frontal cortices, as well as in different amygdala nuclei, with the exception of the central amygdala. It is interesting to point out that this last observation also goes in the same direction as the results obtained in the present study.

Although the mechanisms responsible for the decreases in Fos-ir still need to be elucidated, one of the hypotheses concerning HE etiopathogeny suggests that the behavioral deficits induced by this condition are possibly related to alterations in glutamatemediated neurotransmission. A key role for ammonia in the pathogenesis of $\mathrm{HE}$ has been extensively supported by both clinical and experimental data (Gerber and Schomerus 2000, Vaquero et al. 2003, Jover et al. 2006, Khungar and Poordad, 2012). Ammonia crosses the blood-brain barrier mainly through the transendothelial route, using potassium channels and transporters or by replacing other cations with comparable hydrated radius (for a review see Skowrońska and Albrecht 2012). In the brain, the synthesis of glutamate is linked to a substrate cycle involving glutamine metabolism (Bak et al. 2006) in neurons and astrocytes. As previously mentioned (Phongsamran et al. 2010), glutamine synthesis is altered in response to increases in ammonia levels. Reduced glutamate levels have consistently been observed in brain homogenates from rats with acute liver failure (Hilgier and Olson 1994) and from patients who died from hepatic coma (Lavoie et al. 1987). Thus, one possibility (to be further evaluated) is that the increases in ammonia levels are related to decreases in glutamate neurotransmission and, consequently, to the decreases in Fos-ir observed.

In conclusion, the results of the present study indicate that the BDL model induces anxiety-like behavior and decreases in the activation of two anxiety-mediating brain regions, the intermediate part of the lateral septal nucleus and the medial amygdalar nucleus, which is possibly related to the increases in ammonia plasma levels detected. Nevertheless, if and how increases in ammonia plasma levels may lead to anxious behavior and decreases in the activation of anxiety-related circuits still deserves investigation.

\section{ACKNOWLEDGMENTS}

This work was supported by Conselho Nacional de Desenvolvimento Científico e Tecnológico $(\mathrm{CNPq})$ and Fundação de Amparo à Pesquisa do Estado de São Paulo (FAPESP), Brazil. Measurements of ammonia plasma levels were 
performed at the Associação Fundo de Incentivo à Psicofarmacologia (AFIP/SP), São Paulo, Brazil. J.C.B. is an Investigator for the CNPq.

\section{RESUMO}

A Encefalopatia hepática (HE) engloba uma variedade de sintomas neuropsiquiátricos, incluindo ansiedade e disfunção psicomotora. Embora seja uma complicação frequente da cirrose hepática, os substratos neurobiológicos responsáveis por suas manifestações clínicas são em grande parte desconhecidos. No presente estudo, ratos Wistar machos foram submetidos ao procedimento cirúrgico de ligação e secção do ducto biliar (BDL; bile-duct ligation), para indução da cirrose hepática e, no $21^{\circ}$ dia após a cirurgia, submetidos aos testes comportamentais no labirinto em cruz elevado (LCE) e campo aberto para avaliação da ansiedade e atividade locomotora. A análise da imunorreatividade à proteína Fos (Fos-ir) foi utilizada para melhor compreender as alterações neurobiológicas presentes nos animais do grupo BDL. Foi realizada a quantificação da concentração de amônia plasmática e análise histopatológica dos fígados. Os ratos do grupo BDL mostraram diminuição significativa na porcentagem de entradas e tempo gasto nos braços abertos do LCE, caracterizando efeito ansiogênico. Estes animais também apresentaram redução significativa na Fos-ir no núcleo septal lateral e núcleo medial da amígdala. A concentração plasmática de amônia foi significativamente mais elevada que a do grupo sham e o diagnóstico de cirrose foi confirmado por análise histopatológica. Estes resultados indicam que o modelo de $\mathrm{HE}$ induzido por BDL induz efeito ansiogênico possivelmente relacionado à ativação de circuitos mediadores da ansiedade e à hiperamonemia.

Palavras-chave: ansiedade, ligação do ducto biliar, encefalopatia hepática, atividade locomotora.

\section{REFERENCES}

Ahboucha S, Jiang W, Chatauret N, Mamer O, Baker GB AND BUTTERWORTH RF. 2008. Indomethacin improves locomotor deficit and reduces brain concentrations of neuroinhibitory steroids in rats following portacaval anastomosis. Neurogastroenterol Motil 20: 949-957.
AlBRECHT J AND JONES EA. 1999. Hepatic encephalopathy: molecular mechanisms underlying the clinical syndrome. J Neurol Sci 170: 138-146.

Assimakopoulos SF AND Vagianos CE. 2009. Bile duct ligation in rats: A reliable model of hepatorenal syndrome? World J Gastroenterol 15: 121-123.

BAK LK, Schousboe A AND WAAGepetersen HS. 2006. The glutamate/GABA-glutamine cycle: aspects of transport, neurotransmitter homeostasis and ammonia transfer. J Neurochem 98: 641-653.

Blei AT AND CóRdoBA J. 2001. Hepatic encephalopathy. Am J Gastroenterol 96: 1968-1976.

BUTTERWORTH RF. 2003. Hepatic encephalopathy. Alcohol Res Health 27: 240-246.

CANTERAS N. 2002. The medial hypothalamic defensive system: hodological organization and functional implications. Pharmacol Biochem Behav 71: 481-491.

CRUZ AP, FREI F AND GRAEFF FG. 1994. Ethopharmacological analysis of rat behavior on the elevated plus-maze. Pharmacol Biochem Behav 49: 171-176.

De Andrade JS, Abrão RO, Céspedes IC, Garcia MC, NAscimento JO, Spadari-BratFisch RC, MElo LL, Da SILVA RCAND VIANA MB. 2012. Acute restraint differently alters defensive responses and Fos immunoreactivity in the rat brain. Behav Brain Res 232: 20-29.

Diniz L, Dos Santos TB, BritTo LR, CÉspedes IC, Garcia MC, Spadari-BratFisch RC, Medalha CC, De Castro GM, Montesano FT and Viana MB. 2013. Effects of chronic treatment with corticosterone and imipramine on Fos immunoreactivity and adult hippocampal neurogenesis. Behav Brain Res 238: 170-177.

FERENCIP,LOCKWOOD A, MULLENK, TARTER R, WEISSENBORN K AND BLEI AT. 1998. Hepatic encephalopathy-definition, nomenclature, diagnosis, and quantification: final report of the working party at the 11th World Congresses of Gastroenterology, Vienna. Hepatology 35: 716-721.

GARCIA-TSAO G. 2001. Current management of the complications of cirrhosis and portal hypertension: variceal hemorrhage, ascites, and spontaneous bacterial peritonitis. Gastroenterology 120: 726-748.

GERBER T AND SCHOMERUS H. 2000. Hepatic encephalopathy in liver cirrhosis: pathogenesis, diagnosis and management. Drugs 60: 1353-1370.

GRAY JA. 1987. The neuropsychology of anxiety. Oxford: Oxford University Press.

GRAY JA AND MCNAUGHTON N. 2001. The neuropsychology of anxiety. Oxford: Oxford University Press.

Herdade KC, Strauss CV, ZANGRossi Jr H AND Viana MB 2006. Effects of medial amygdala inactivation on a panicrelated behavior. Behav Brain Res 172: 316-323.

HILGIER W AND OlSON JE. 1994. Brain ion and amino acid contents during edema development in hepatic encephalopathy. J Neurochem 62: 197-204.

HSU SM AND RAINE L. 1981. Protein A, avidin, and biotin in immunohistochemistry. J Histochem Cytochem 29: 13491353. 
JOVER R ET AL. 2006. Brain edema and inflammatory activation in bile duct ligated rats with diet-induced hyperammonemia: A model of hepatic encephalopathy in cirrhosis. Hepatology 43: 1257-1266.

KANG N, BAUM MJ AND ChERry JA. 2009. A direct main olfactory bulb projection to the 'vomeronasal' amygdala in female mice selectively responds to volatile pheromons from males. Eur J Neurosci 29: 624-634.

Kevetter GA And Winans SS. 1981. Connections of the corticomedial amygdala in the golden hamster.I.Efferents of the Vomeronasal amygdala. J Comp Neurol 197: 81-98.

KHUNGAR V AND POORDAD F. 2012. Hepathic encephalopathy. Clin Liver Dis 16: 301-320.

KIM WR, Lindor KD, LOCKE GR, THERnEAU TM, Homburger HA, BATTS KP, YAwn BP, Petz JL, MELTON LJ AND DICKSON ER. 2000. Epidemiology and natural history of primary biliary cirrhosis in a US community. Gastroenterology 119: 1631-1636.

Kontouras J, Billing BH and Scheuer PJ. 1984. Prolonged bile duct obstruction: a new experimental model for cirrhosis in the rat. Br J Exp Path 65: 305-311.

LAVOIE J, Giguere JF, LAYRARGUES GP AND BUTTERWORTH RF. 1987. Amino acid changes in autopsied brain tissue from cirrhotic patients with hepatic encephalopathy. J Neurochem 49: 692-697.

LEKE R ET AL. 2012. Impairment of the organization of locomotor and exploratory behaviors in bile duct-ligated rats. PLoS One 7: e36322.

MARAS PM AND PETRUlis A. 2010. The anterior medial amygdala transmits sexual odor information to the posterior medial amygdala and related forebrain nuclei. Eur J Neurosci 32: 469-482.

MA S AND MORILAK DA. 2005. Norepinephrine release in medial amygdala facilitates activation of the hypothalamicpituitary-adrenal axis in response to acute immobilization stress. J Neuroendocrinol 17: 22-28.

MCNAUGhton N AND CORR PJ. 2004. A two-dimensional neuropsychology of defense: fear/anxiety and defensive distance. Neurosci Biobehav Rev 28: 285-305.

Muigg P, Hetzenauer A, Hauer G, Hauschild M, Gaburro S, Frank E, Landgraf R AND Singewald N. 2008. Impaired extinction of learned fear in rats selectively bred for high anxiety evidence of altered neuronal processing in prefrontal-amygdala pathways. Eur J Neurosci 28: 2299-2309.

NiIMI K, HORIE S, YOKOSUKA M, KAWAKAMI-MORI F, TANAKA K, FUKAYAMA H AND SAHARA Y. 2012. Heterogeneous electrophysiological and morphological properties of neurons in the mouse medial amygdala in vitro. Brain Res 1480: 41-52.

PAXINOS G AND WATSON C. 2008. The rat brain in stereotaxic coordinates: compact sixth edition. Sidney: Academic Press.

Pellow S, Chopin P, File SE ANd Briley M. 1985. Validation of open: closed arm entries in the elevated plus-maze as a measure of anxiety in the rat. J Neurosci Meth 14: $149-167$.
Pereira RC, Santos Ras, Oliveira EA, Leite VHR, Dias FLC, REZENDE AS, COSTA LP, BARCELOS LS, TEIXEIRA MM AND SimÕES E SiLVA AC. 2008. Development of hepatorenal syndrome in bile duct ligated rats. World $\mathrm{J}$ Gastroenterol 14: 4505-4511.

Phongsamran PV, Kim JW, ABBotT JC AND RosenblatT A. 2010. Pharmacotherapy for hepatic encephalopathy. Drugs 70: 1131-1148.

ROYCE JR. 1977. On the construct validity of open-field measures. Psychol Bull 84: 1098-1106.

SAKAmoto M, PERry W, Hilsabeck RC, BARAKAT F AND HASSANEIN T. 2012. Assessment and usefulness of clinical scales for semiquantification of overt hepatic encephalopathy. Clin Liver Dis 16: 27-42.

SCHUPPAN D AND AFDHAL NH. 2008. Liver cirrhosis. Lancet 371: 838-851.

Sergeeva OA, Schulz D, Doreulee N, Ponomarenko AA, Selbach O, Borsch E, Kircheis G, Huston JP, HÄUSSINGER D AND HAAS HL. 2005. Deficits in corticostriatal synaptic plasticity and behavioral habituation in rats with portacaval anastomosis. Neuroscience 134: 1091-1098.

SKOWROŃSKA M AND ALBRECHT J. 2012. Alterations of blood brain barrier function in hyperammonemia: an overview. Neurotox Res 21: 236-244.

SunMonu TA, AdeKanle O, Komolafe MA AND NdububA DA. 2012. Cognitive function in patients with liver cirrhosis without overt hepatic encephalopathy: assessment using an automated neuropsychological test battery. Arab J Gastroenterol 13: 4-8.

THOMAS E. 1988. Forebrain mechanisms in the relief of fear: the role of the lateral septum. Psychobiology 16: 36-44.

TREIT D AND MENARD J. 2000. The septum and anxiety. In Numan R, editor, The behavioural neuroscience of the septal region, New York: Springer-Verlag, p. 210-233.

VAquero J, Chung C, Cahill ME and Blei AT. 2003. Pathogenesis of hepatic encephalopathy in acute liver failure. Semin Liver Dis 23: 259-269.

WEISSENBORN K, BURCHERT W, BOKEMEYER M, EHRENHEIM C, Kolbe H, Manns MP And Dengler R. 1997. Regional differences of cerebral glucose metabolism in patients with liver cirrhosis depending on the grade of portosystemic encephalopathy (PSE). In: Record C and Al Mardini H (Eds), Advances in Hepatic Encephalopathy and Metabolism in Liver Disease. Newcastle upon Tyne: Medical Faculty of the University of Newcastle upon Tyne, p. 359-363.

Yadin E, Thomas E, GrishKat HL and Strickland CE. 1993. The role of the lateral septum in anxiolysis. Physiol Behav 53: 1077-1083. 
